\title{
Multiphase solid inclusions in UHP eclogite from the Dabie orogen: constraints on anatectic melts during continental collision
}

\author{
Xiao-Ying Gao \\ CAS Key Laboratory of Crust-Mantle Materials and Environments, School of Earth and Space Science, \\ University of Science and Technology of China, Hefei, China, gaoying@ustc.edu.cn
}

\section{Introduction}

By definition, MS inclusions are a kind of mineral inclusions that consist of more than one solid mineral phases, with or without a vapor or fluid phase. They generally occur at a microscale and thus are observable under a microscope. Philippot and Selverstone (1991) reported for the first time the occurrence of MS inclusions in pyrope from coesite-bearing whiteschist at Dora-Maira in Western Alps. Subsequently, many kinds of MS inclusions have been reported in high-pressure (HP) to UHP metamorphic rocks worldwide. The study of MS inclusions provide important records of crustal anatexis and melt evolution in collisional orogens. Furthermore, more studies have been carried out for MS inclusions in migmatites and granulites (e.g., Cesare et al., 2011; Bartoli et al., 2013), the products of crustal anataxis at medium to high pressures.

\section{The microstructure and chemical composition of MS inclusions}

The MS inclusions may be small droplets of anatectic melts trapped in pritectic minerals, which were then crystallized to polycrystalline aggregates. Usually, the average size of MS inclusion is $<25$ $\mu \mathrm{m}$, but exceptionally large inclusions may reach up to $\sim 00 \mathrm{~mm}$ in peritectic minerals (such as garnet, omphacite, kyanite, zircon). Most of inclusion exhibit polygonal to negative crystal shapes, depending on the crystallographic control of the host mineral (Fig. 1). The abundance of negative crystal shapes and the occurrence of "necking-down" phenomena (Acosta-Vigil et al., 2007) indicates that solution/precipitation processes were efficient in modifying the shape of inclusion in order to diminish the surface free energy (Roedder, 1984). Different phases in MS inclusions mostly occur in different forms. For micro-inclusions with palisade texture, K-feldspar tends to be concentrated within the palisade or at the contact between the palisade and the core (Fig. 1a). Light grey large crystals occur as interstitials between K-feldspar (dark grey) grains, frequently resembling that of a holly leaf. In the edge of some inclusions, they exhibit the wedge-shaped off-shoot structure (Fig. 1), suggesting reequilibration between the inclusion and its host mineral. They typically contain a great and variable number of solids and lack a visible fluid phase (i.e. $\mathrm{H}_{2} \mathrm{O}, \mathrm{N}_{2}, \mathrm{CO}_{2}$ ). The former presence of a fluid phase may be assumed, because of the regular presence of one or more deformed cavities (voids) within inclusions.

The major and trace element compositions of MS inclusions can provide important clues to their origin (e.g., Gao et al., 2012, 2013; Korsakov and Hermann, 2006; Zeng et al., 2009). However, the MS inclusions commonly exhibit varying lithochemical compositions from felsic to mafic, but primarily felsic. Generally, silicate MS inclusions are the most common ones in UHP metamorphic rocks. Felsic MS inclusions are primarily composed of quartz, K-feldspar and/or plagioclase. Generally, these felsic MS inclusions found in UHP eclogites from the Dabie-Sulu orogenic belt exhibit highly heterogeneous major element compositions (Fig. 2). These MS inclusions can be categoried into three types in terms of their mineral paragenesis: (1) feldspar (K-feldspar or albite) + quartz; (2) feldspar + quartz \pm barite; (3) calcite + feldspar + quartz.

Zeng et al. (2009) observed MS inclusions of K-feldspar + albite + quartz + epidote with textures similar to the other K-feldspar + quartz inclusions in omphacite grains of eclogite from the Sulu orogen. Gao et al. (2012, 2013) observed various types of K-bearing MS inclusions in garnet of the UHP eclogite in the Dabie orogen, which are composed of not only felsic minerals such as quartz, Kfeldspar, albite and plagioclase, but also minor amounts of mafic minerals (epidote) and sulfate minerals (barite). Chen et al. (2014) also found similar MS inclusions in both garnet and omphacite for zoisite-bearing eclogite from the UHP metamorphic zone in the Sulu orogen. However, these types of MS inclusions found by Chen et al. (2014) are primarily composed of Na-bearing plagioclase. 
In general, the MS inclusions found in UHP eclogites from the Dabie-Sulu orogenic belt exhibit very heterogeneous bulk compositions (Zeng et al., 2009; Gao et al., 2009; Chen et al., 2014). The bulk composition of major elements in MS inclusions was estimated by high resolution BSE images, on the assumption that the mineral modal contents estimated from BSE for the MS inclusions exposed on host surface can represent the bulk MS inclusions. Although this assumption can potentially introduce further uncertainty for estimate of the bulk composition of MS inclusions (Cesare et al., 2011), it may only account for the large scatter but do not change the general feature of the data. It is illustrated in the Qz-An-Ab normative diagram (Fig. 2). Obviously, the Qz + Pl + Kfs inclusions show a wide range of $\mathrm{SiO}_{2}$ and $\mathrm{Al}_{2} \mathrm{O}_{3}$ values, whereas the Na-bearing inclusions of $\mathrm{Qz}+\mathrm{Pl}$ generally exhibits lower $\mathrm{SiO}_{2}$ values and higher $\mathrm{Al}_{2} \mathrm{O}_{3}$ values. The $\mathrm{Kfs}+\mathrm{Qz}$ inclusions are essentially composed of $\mathrm{SiO}_{2}$ (63.8-91.9 wt\%), $\mathrm{Al}_{2} \mathrm{O}_{3}$ values (3.34-19.0 wt\%) and $\mathrm{K}_{2} \mathrm{O}$ (2.1-15.1 wt\%). The variable concentrations of $\mathrm{SiO}_{2}, \mathrm{Al}_{2} \mathrm{O}_{3}, \mathrm{~K}_{2} \mathrm{O}$ and $\mathrm{Na}_{2} \mathrm{O}$ reflect variable amounts of the major phases such as plagioclase, $\mathrm{K}-$ feldspar and quartz within the different MS inclusions in the host minerals. The Kfs-bearing inclusions have much lower $\mathrm{Ca}$ and $\mathrm{Al}$ contents, and remarkably higher $\mathrm{K}_{2} \mathrm{O}$ and $\mathrm{SiO}_{2}$ contents (some larger than $80 \mathrm{wt} \%$ ) than the quenched melts in the experimental studies of natural eclogites and the crystallized melt inclusions hosted in peritectic garnet of migmatites and granulite that are formed at different P-T-X $\left(\mathrm{H}_{2} \mathrm{O}\right)$ conditions and by mineralogical reaction of dehydration melting (Cesare et al., 2011; Bartoli et al., 2013).
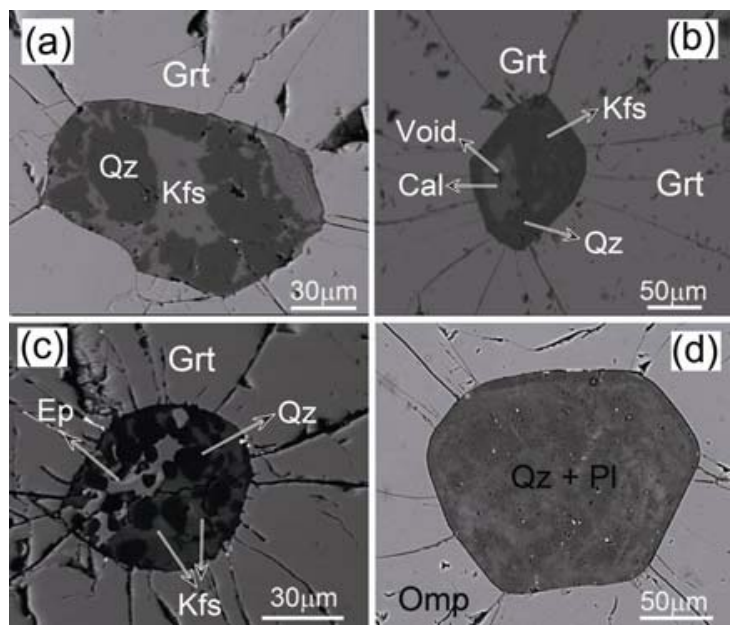

Figure 1: BSE images of MS inclusions in garnet and omphacite from UHP metamorphic rocks.

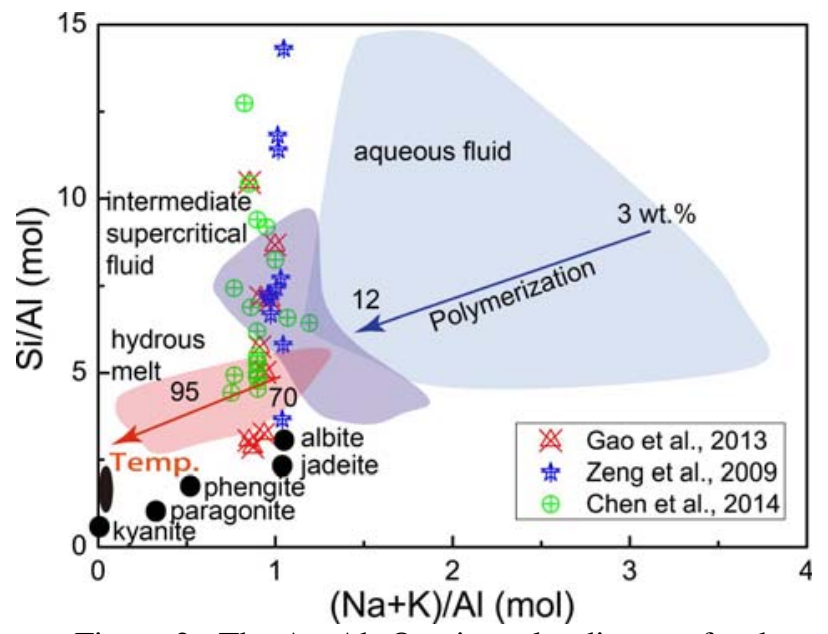

Figure 2: The An-Ab-Or triangular diagram for the major element compositions of bulk MS inclusions.

It is important to determine the trace element composition of silicate MS inclusions despite possible limitations in analytical techniques. In order to estimate the trace element composition of silicate MS inclusions in detail, two different approaches of laser sampling were utilized by Gao et al. (2013). As a consequence, the two approaches yield relatively consistent results of major and trace element compositions. The trace elements analysis of Kfs-bearing MS inclusions by Gao et al. (2014) exhibit enrichment in LILE, $\mathrm{Sr}$ and Pb but depletion in HFSE in the primitive mantle-normalized spidergram. However, Chen et al. (2014) found that trace elements in Na-bearing MS inclusions generally show very low concentrations except LILE such as $\mathrm{Sr}$, Ba and Rb. These features suggest different origins for the different types of MS inclusions. Many MS inclusions show variably high K, $\mathrm{Rb}$ and $\mathrm{Sr}$ abundances, suggesting that the breakdown of hydrous minerals as phengite or paragonite is a basic cause for partial melting of UHP eclogites. These MS inclusions also exhibit consistently low HFSE and Y contents, suggesting that partial melting of the UHP eclogite takes place in the stability fields of rutile and garnet. Consequently, the trace element composition of MS inclusions provides a proxy for that of hydrous silicate melts derived from dehydration melting of the UHP eclogite during the continental collision. An integrated study of petrology, mineralogy and geochemistry indicates that MS inclusions represent the anatectic products of UHP eclogites during continental collision, with possible immiscibility between aqueous solutions and hydrous melts (Zeng et al., 2009a; Gao et al., 2012, 2013; Chen et al., 2014). The K-bearing MS inclusions are generally interpreted as crystallizing from felsic melts due to the dehydration melting of K-bearing hydrous 
minerals like phengite in the eclogites (e.g., Gao et al., 2012, 2013). On the other hand, some MS inclusions show remarkably higher $\mathrm{Na}$ contents, and they would be primarily derived from dehydration melting of paragonite (Chen et al., 2014).

Beside silicate MS inclusions, carbonate MS inclusions were also found not only in UHP marbles (Korsakov and Hermann, 2006) and eclogites (Gao et al., 2014) but also in low-to-medium pressure migmatites (Ferrero et al., 2016). Gao et al. (2014) found calcite and polyphase carbonate-silicate inclusions in garnet from UHP eclogite from the Daibe orogen, where MS inclusions are primarily composed of variable proportions of carbonate and silicate minerals such as calcite, quartz, K-feldspar and plagioclase with occasional occurrences of magnetite, zircon and barite. Two groups of MS inclusions are categorized according to the proportions of carbonate and silicate phases. Group I is carbonate-dominated with variable proportions of silicate minerals, and Group II is silicate-dominated with small proportions of carbonates. Group I inclusions exhibit remarkably lower REE contents than Group II inclusions, with significant LREE enrichment and large fractionation between LREE and HREE in the chondrite-normalized REE diagram. In contrast, Group II inclusions show rather flat REE patterns with insignificant fractionation between LREE and HREE. In the primitive mantlenormalized spidergram, Group I inclusions exhibit positive anomalies of $\mathrm{Zr}$ and Hf, whereas Group II inclusions show negative anomalies of $\mathrm{Zr}$ and Hf. Nevertheless, both groups exhibit positive anomalies in $\mathrm{Ba}, \mathrm{U}, \mathrm{Pb}$ and $\mathrm{Sr}$, but negative anomalies in $\mathrm{Nb}$ and $\mathrm{Ta}$, resembling the composition of common continental crust. Group I inclusions have higher Ba and U contents than Group II inclusions. Combined with petrological observations, the two groups of MS inclusions are interpreted as having crystallized from composite silicate and carbonate melts during continental collision. The differences in trace element composition between the two groups are primarily attributed to the proportions of carbonate and silicate phases in the MS inclusions. The occurrence of carbonate and silicate MS inclusions in the UHP domain garnet and clinopyroxene indicates the presence of both carbonate and silicate melts during mineral growth (Gao et al., 2014; Korsakov and Hermann, 2006). The MS inclusions would have crystallized from such silicate-carbonate melts at mantle depths. The similar immiscibility between carbonatitic and granitic melts is preserved as polycrystalline inclusions with a characteristic enrichment in $\mathrm{Ba}$, Sr and LREE in the lower crust (Ferrero et al., 2016). The identification and characterization of these MS inclusions in peritectic minerals provides new insights into the anatectic conditions and time of UHP metamorphic rocks, which has great bearing on the chemical geodynamics of subduction zones.

\section{References}

Cesare, B., Acosta-Vigil, A., Ferrero, S., Bartoli, O., 2011. Melt inclusions in migmatites and granulites. Journal of the Virtual Explorer 38, paper 2; doi: 10.3809/jvirtex.2011.00268.

Chen, Y.-X., Zheng, Y.-F., Gao, X.Y., Hu, Z.C., 2014. Multiphase solid inclusions in zoisite-bearing eclogite: evidence for partial melting of ultrahigh-pressure metamorphic rocks during continental collision. Lithos 200-201, 1-21.

Ferrero, S., Wunder, B., Ziemann, M.A., Wälle, M., O'Brien, P.J., 2016. Carbonatitic and granitic melts produced under conditions of primary immiscibility during anatexis in the lower crust. Earth and Planetary Science Letters 454, 121-131.

Gao, X.-Y., Zheng, Y.-F., Chen, Y.-X., 2012. Dehydration melting of ultrahigh-pressure eclogite in the Dabie orogen: evidence from multiphase solid inclusions in garnet. Journal of Metamorphic Geology 30, 193-212.

Gao, X.-Y., Zheng, Y.-F., Chen, Y.-X., Hu, Z.C., 2013. Trace element composition of continentally subducted slab-derived melt: insight from multiphase solid inclusions in ultrahigh-pressure eclogite in the Dabie orogen. Journal of Metamorphic Geology 31, 453-468.

Gao, X.Y., Zheng, Y.F., Chen, Y.X., Hu, Z.C., 2014. Composite carbonate and silicate multiphase solid inclusions in metamorphic garnet from ultrahigh-Peclogite in the Dabie orogen. Journal of Metamorphic Geology 32, 961-980.

Korsakov, A.V., Hermann, J., 2006. Silicate and carbonate melt inclusions associated with diamonds in deeply subducted carbonate rocks. Earth and Planetary Science Letters 241, 104-118.

Zeng, L.S., Liang, F.H., Asimow, P., Chen, F.Y., Chen, J., 2009. Partial melting of deeply subducted continental crust and the formation of quartzofeldspathic polyphase inclusions in the Sulu UHP eclogites. Chinese Science Bulletin 54, 2580-2594. 